\title{
Association between Treatment Response and Potential Indicators of Efficacy and Safety in a Phase III Trial of Decitabine in Older Patients with Acute Myeloid Leukemia
}

\author{
Mark D. Minden ${ }^{1 *}$, Christopher Arthur ${ }^{2}$, Jiři Mayer ${ }^{3}$, Mark M. Jones ${ }^{4}$, Erhan Berrak ${ }^{4}$ and Hagop Kantarjian ${ }^{5}$ \\ ${ }^{1}$ Ontario Cancer Institute/Princess Margaret Hospital, Division of Stem Cell and Developmental Biology, Toronto, Ontario, Canada \\ ${ }^{2}$ Royal North Shore Hospital, Department of Haematology, St. Leonards, Australia \\ ${ }^{3}$ Masaryk University Hospital Brno, and CEITEC, Masaryk University, Czech Republic \\ ${ }^{4}$ Eisai Inc., Oncology Product Creation Unit, Woodcliff Lake, NJ, USA \\ ${ }^{5}$ The University of Texas MD Anderson Cancer Center, Department of Leukemia, Houston, TX, USA
}

*Corresponding author: Mark D. Minden, Professor of Medicine, Ontario Cancer Institute/Princess Margaret Hospital, 9th Rm 9-113, 610 University Avenue Toronto, Ontario M5G 2M9, Canada, Tel: 4169464501 2838; Fax: 416-946-6546; E-mail: minden@uhnres.utoronto.ca

Received date: Dec 04, 2014, Accepted date: Feb 04, 2015, Publication date: Feb 10, 2015

Copyright: (C) 2015 Minden MD, et al. This is an open-access article distributed under the terms of the Creative Commons Attribution License, which permits unrestricted use, distribution, and reproduction in any medium, provided the original author and source are credited.

\begin{abstract}
Objective: In a phase III trial, 485 patients aged 65 years or older with newly diagnosed acute myeloid leukemia received decitabine $\left(20 \mathrm{mg} / \mathrm{m}^{2}\right.$ intravenously for 5 days) or treatment of choice (supportive care or cytarabine 20 $\mathrm{mg} / \mathrm{m}^{2}$ subcutaneously for 10 days) every 4 weeks. This post hoc analysis investigated potential efficacy and safety indicators and treatment response.
\end{abstract}

Methods: Transfusions, intravenous antibiotics, and dose modifications were tabulated for responders (morphologic complete remission, complete remission with incomplete blood count recovery, or partial response) and nonresponders.

Results: Median overall survival was significantly greater for treatment responders than for nonresponders (17.4 months vs 4.3 months; $P<0.0001)$. Nonresponders had more intravenous antibiotic use $(P=0.024)$, dose modifications per cycle $(P=0.016)$, and platelet or red blood cell transfusions per cycle $(P<0.0001)$.

Conclusions: Response to decitabine or to treatment of choice may be associated with certain indicators in older patients with acute myeloid leukemia.

Keywords: Dacogen; Decitabine; Acute myeloid leukemia; Prognosis; Leukemia; Adult

\section{Introduction}

Acute myeloid leukemia (AML) is a common adult leukemia, the incidence of which is increasing as the population ages [1]. However, treatments for older patients, particularly those with comorbidities, are limited, with older patients being more susceptible to treatmentrelated complications [2]. United States and European treatment guidelines for AML (European LeukemiaNet [3], National Comprehensive Cancer Network [4]) were recently updated to include the following therapeutic options for AML: low-intensity cytarabine, 5-azacytidine, and decitabine.

Decitabine is a hypomethylating agent indicated in the United States and many ex-European Union countries for the treatment of previously treated or untreated de novo and secondary myelodysplastic syndrome (MDS) of all French-American-British subtypes and intermediate-1, intermediate-2, and high-risk International Prognostic Scoring System groups [5]. In two phase II studies, decitabine $20 \mathrm{mg} / \mathrm{m}^{2}$ administered as a daily 1-hour intravenous (IV) infusion either on days 1 through 10 every 4 weeks [6] or for 5 consecutive days every 4 weeks [7] demonstrated activity in patients aged 60 years or older with AML and poor- or intermediaterisk cytogenetics [6,7].

In July 2012, the results of a large, international, multicenter, openlabel phase III trial in 485 patients aged 65 years or older with newly diagnosed de novo or secondary AML and poor- or intermediate-risk cytogenetics were published [8]. Patients in the study were randomized to receive, every 4 weeks, either decitabine $20 \mathrm{mg} / \mathrm{m}^{2}$ (1hour IV infusion for 5 consecutive days) or treatment of choice; the latter was either supportive care or cytarabine $\left(20 \mathrm{mg} / \mathrm{m}^{2}\right.$ subcutaneous injection for 10 consecutive days) [8].

The primary efficacy analysis (October 2009) indicated a nonsignificant but favorable trend toward increased median overall survival with decitabine (7.7 months; 95\% CI: 6.2-9.2 months) compared with treatment of choice (5.0 months; 95\% CI: $4.3-6.3$ months), and an estimated hazard ratio of $0.85(\mathrm{P}=0.108)$.

In a post hoc analysis of mature data (October 2010), median overall survival was the same as in the 2009 analysis, but the hazard ratio had improved $(0.82$; $95 \% \mathrm{CI}$ : $0.68-0.99$; nominal $\mathrm{P}=0.037$ ) in favor of decitabine. The present post hoc analysis investigated the relationship between response to treatment (decitabine or treatment of choice) and various potential indicators of efficacy and safety, specifically, IV antibiotic use, red blood cell and platelet transfusion 
Citation: Minden MD, Arthur C, Mayer J, Jones MM, Berrak E, et al. (2015) Association between Treatment Response and Potential Indicators of Efficacy and Safety in a Phase III Trial of Decitabine in Older Patients with Acute Myeloid Leukemia. J Blood Disorders Transf 6: 251. doi:10.4172/2155-9864.1000251

Page 2 of 5

requirements, and the requirement for dose modifications (dose reductions or delays), in this older patient population.

\section{Methods}

In the primary analysis of the phase III trial, 396 deaths were reported at the clinical cutoff date in October 2009. For this post hoc analysis, we used a mature data set with a cutoff date of October 29 , 2010. Data were based on the intent-to-treat population, with 446 deaths, 227 in the treatment of choice group and 219 in the decitabine group, reported at this time point [8].

Data were analyzed for patients who had both response to treatment and parameter data available. Response to treatment in either the decitabine or treatment of choice group was defined as morphologic complete remission (CR), CR with incomplete blood count recovery $(\mathrm{CRi})$, or partial response (PR). Patients received treatment until they experienced relapse or progressive disease, unacceptable toxicity, lack of clinical benefit, an intercurrent illness preventing treatment, or death, or at the physician's or patient's request [8].

Patients who were not responders were classified as 'nonresponders,' which included patients who did not respond to either decitabine or cytarabine and patients who received supportive care.

Transfusion requirements (red blood cells or platelets) were determined by the treating physician and were analyzed based on the number of transfusion episodes per patient treatment cycle.
Intravenous antibiotic use was analyzed based on the number of patients who received at least one IV antibiotic.

Dose modifications were analyzed based on the number of patients with one or more dose reductions or delays per patient treatment cycle. Each of these parameters was tabulated for responders and nonresponders to decitabine or treatment of choice during the treatment period. Transfusion episodes were also analyzed by baseline white blood cell count $\left(\leq 10 \times 10^{9} / \mathrm{L}\right.$ or $\left.>10 \times 10^{9} / \mathrm{L}\right)$.

Statistical tests were performed using a zero-inflated Poisson regression model to compare the mean number of transfusion episodes per treatment cycle, a logistics regression model to compare the proportion of patients with dose modifications per treatment cycle, and a 2-proportion Z-test to compare the proportion of patients who required the use of antibiotics.

\section{Results}

\section{Patients}

The overall patient population comprised 485 patients (median age, 73 years) with newly diagnosed AML who received either decitabine $(n=242)$ or treatment of choice $(n=243 ; n=215$ for cytarabine; $\mathrm{n}=28$ for supportive care) (Table 1 ).

Most patients had intermediate-risk cytogenetics and an ECOG performance status of 0 or 1 at baseline.

\begin{tabular}{|c|c|c|c|c|c|c|c|c|c|c|}
\hline \multirow{4}{*}{ Characteristic } & \multicolumn{6}{|c|}{ Treatment of choice (TC) } & \multirow{2}{*}{\multicolumn{2}{|c|}{$\begin{array}{l}\text { Decitabine } \\
(n=242)\end{array}$}} & \multirow{2}{*}{\multicolumn{2}{|c|}{$\begin{array}{l}\text { All patients } \\
(\mathrm{N}=485)\end{array}$}} \\
\hline & \multicolumn{2}{|c|}{ Supportive care } & \multicolumn{2}{|l|}{ Cytarabine } & \multicolumn{2}{|l|}{ Total TC } & & & & \\
\hline & \multicolumn{2}{|l|}{$(n=28)$} & \multicolumn{2}{|l|}{$(n=215)$} & \multicolumn{2}{|l|}{$(n=243)$} & \multirow[b]{2}{*}{$\begin{array}{l}\text { No. of } \\
\text { Patients }\end{array}$} & \multirow[b]{2}{*}{$\%$} & \multirow[b]{2}{*}{$\begin{array}{l}\text { No. of } \\
\text { Patients }\end{array}$} & \multirow[b]{2}{*}{$\%$} \\
\hline & $\begin{array}{l}\text { No. of } \\
\text { Patients }\end{array}$ & $\%$ & $\begin{array}{l}\text { No. of } \\
\text { Patients }\end{array}$ & $\%$ & $\begin{array}{l}\text { No. of } \\
\text { Patients }\end{array}$ & $\%$ & & & & \\
\hline \multicolumn{11}{|l|}{ Age, years } \\
\hline Median & 75 & & 73 & & 73 & & 73 & & 73 & \\
\hline Range & $66-86$ & & $64-91$ & & $64-91$ & & $64-89$ & & $64-91$ & \\
\hline $65-69$ & 5 & 17.9 & 64 & 29.8 & 69 & $28.4^{*}$ & 68 & $28.1 \dagger$ & 137 & 28.2 \\
\hline$\geq 70$ & 23 & 82.1 & 150 & 69.8 & 173 & 71.2 & 171 & 70.7 & 344 & 70.9 \\
\hline \multicolumn{11}{|l|}{ Sex } \\
\hline Female & 8 & 28.6 & 84 & 39.1 & 92 & 37.9 & 105 & 43.4 & 197 & 40.6 \\
\hline Male & 20 & 71.4 & 131 & 60.9 & 151 & 62.1 & 137 & 56.6 & 288 & 59.4 \\
\hline \multicolumn{11}{|l|}{ BSA, $\mathbf{m}^{2}$} \\
\hline Median & 1.75 & & 1.8 & & 1.8 & & 1.82 & & 1.81 & \\
\hline Range & $1.3-2.4$ & & $1.4-2.7$ & & $1.3-2.7$ & & $1.4-2.6$ & & $1.3-2.7$ & \\
\hline \multicolumn{11}{|c|}{ Time since AML diagnosis, days } \\
\hline Median & 27 & & 15 & & 15 & & 14 & & 15 & \\
\hline Range & $0.0-363.0$ & & $0.0-398.0$ & & $0.0-398.0$ & & $3.0-346.0$ & & $0.0-398.0$ & \\
\hline
\end{tabular}


Citation: Minden MD, Arthur C, Mayer J, Jones MM, Berrak E, et al. (2015) Association between Treatment Response and Potential Indicators of Efficacy and Safety in a Phase III Trial of Decitabine in Older Patients with Acute Myeloid Leukemia. J Blood Disorders Transf 6: 251. doi:10.4172/2155-9864.1000251

Page 3 of 5

\begin{tabular}{|c|c|c|c|c|c|c|c|c|c|c|}
\hline \multicolumn{11}{|l|}{ Type of AML } \\
\hline De novo & 17 & 60.7 & 140 & 65.1 & 157 & 64.6 & 155 & 64 & 312 & 64.3 \\
\hline Secondary & 11 & 39.3 & 73 & 34 & 84 & 34.6 & 87 & 36 & 171 & 35.3 \\
\hline \multicolumn{11}{|c|}{ Bone marrow blasts $\ddagger$} \\
\hline $20 \%-30 \%$ & 5 & 17.9 & 53 & 24.9 & 58 & 24.1 & 65 & 27 & 123 & 25.5 \\
\hline$>30 \%-50 \%$ & 10 & 35.7 & 64 & 30 & 74 & 30.7 & 67 & 27.8 & 141 & 29.3 \\
\hline$>50 \%$ & 11 & 39.3 & 90 & 42.3 & 101 & 41.9 & 105 & 43.69 & 206 & 42.7 \\
\hline \multicolumn{11}{|l|}{ Cytogenetics } \\
\hline Intermediate risk & 20 & 71.4 & 134 & 62.6 & 154 & 63.6 & 152 & 63.1 & 306 & 63.4 \\
\hline Poor risk & 8 & 28.6 & 79 & 36.9 & 87 & 36 & 87 & 36.1 & 174 & 36 \\
\hline \multicolumn{11}{|l|}{ ECOG PS } \\
\hline 0 or 1 & 19 & 67.9 & 164 & 76.3 & 183 & 75.3 & 184 & 76 & 367 & 75.7 \\
\hline 2 & 9 & & 51 & & 60 & & 58 & & 118 & \\
\hline \multicolumn{11}{|l|}{ Hemoglobin, g/dL } \\
\hline Median & 9.3 & & 9.4 & & 9.4 & & 9.3 & & 9.3 & \\
\hline Range & $6.6-10.7$ & & $5.0-12.6$ & & $5.0-12.6$ & & $5.2-15.0$ & & $5.0-15.0$ & \\
\hline \multicolumn{11}{|c|}{ Median white blood cells, $10^{9} / \mathrm{L}$ (range) } \\
\hline Median & 2.73 & & 3.71 & & 3.69 & & 3.1 & & 3.43 & \\
\hline Range & $0.7-26.5$ & & $0.5-80.9$ & & $0.5-80.9$ & & $0.3-127.0$ & & $0.3-127.0$ & \\
\hline
\end{tabular}

Table 1: Patient demographics and baseline clinical characteristics [8]. ${ }^{\star}$ One patient (not included) was aged $<65$ years. $\dagger$ Three patients (not included) were aged 65 years. $¥$ Twelve patients with $<20 \%$ blasts in the safety population included 1 patient with M6 AML (defined by marrow erythroblasts), 3 patients with a misdiagnosis of AML, 5 patients with unknown blast counts at screening, and 3 protocol deviations. AML indicates acute myeloid leukemia; ECOG PS, Eastern Cooperative Oncology Group performance status. Reprinted with permission from Kantarjian et al. [8].

At the time of cutoff, patients had received a median of 4 cycles (range, 1-29) of decitabine, 2 cycles (range, 1-30 cycles) of cytarabine, or 2 cycles (range, 1-28 cycles) of supportive care [8].

\section{Overall survival and response to treatment}

Median overall survival (Table 2) was significantly greater for treatment responders than for nonresponders (17.4 months vs 4.3 months, respectively; $\mathrm{P}<0.0001)$. In the combined treatment groups, the proportion of patients who were responders $(\mathrm{CR}+\mathrm{CRi}+\mathrm{PR})$ was $21.2 \%$ (decitabine, $28.1 \%$; treatment of choice, $14.1 \%$ ).

In the treatment of choice arm, $10.7 \%$ of patients who received supportive care and $14.4 \%$ of patients who received cytarabine were responders.

\begin{tabular}{|c|c|c|c|}
\hline Parameter* & $\begin{array}{l}\text { Nonresponders } \\
\text { to decitabine or treatment of choice }{ }^{\dagger}\end{array}$ & $\begin{array}{l}\text { Responders to decitabine or treatment } \\
\text { of choice }{ }^{\dagger} \\
\text { (CR+CRi+PR) }\end{array}$ & $P$ value \\
\hline Median overall survival, months & 4.3 & 17.4 & $<0.0001^{\ddagger}$ \\
\hline \multicolumn{4}{|c|}{ Intravenous antibiotic use ( $\geq 1$ per patient) } \\
\hline Number of patients & 383 & 102 & \\
\hline Yes, n (\%) & $38(9.9)$ & $3(2.9)$ & $0.024 \S$ \\
\hline
\end{tabular}


Citation: Minden MD, Arthur C, Mayer J, Jones MM, Berrak E, et al. (2015) Association between Treatment Response and Potential Indicators of Efficacy and Safety in a Phase III Trial of Decitabine in Older Patients with Acute Myeloid Leukemia. J Blood Disorders Transf 6: 251. doi:10.4172/2155-9864.1000251

Page 4 of 5

\begin{tabular}{|c|c|c|c|}
\hline \multicolumn{4}{|l|}{ Platelet transfusions (episodes per patient) } \\
\hline Number of patients & 373 & 102 & \\
\hline Mean (SD) & $3.03(3.82)$ & $1.19(2.35)$ & $\begin{array}{l}\mathrm{P} 1<0.0001 \\
\mathrm{P} 2=0.796 "\end{array}$ \\
\hline Median (range) & $1.8(0-21)$ & $0.3(0-14)$ & \\
\hline $\begin{array}{l}\text { Number of transfusions/number of patient } \\
\text { treatment cycles (proportion) }\end{array}$ & $3231 / 1492(2.17)$ & $1025 / 1319(0.78)$ & \\
\hline \multicolumn{4}{|c|}{ Red blood cell transfusions (episodes per patient) } \\
\hline Number of patients & 373 & 102 & \\
\hline Mean (SD) & $2.93(2.54)$ & $1.42(1.47)$ & $\begin{array}{l}\mathrm{P} 1<0.0001 \\
\mathrm{P} 2=0.872^{\|}\end{array}$ \\
\hline Median (range) & $2.3(0-16)$ & $1.1(0-10.5)$ & \\
\hline $\begin{array}{l}\text { Number of transfusions/number of patient } \\
\text { cycles (proportion) }\end{array}$ & 3642 / $1492(2.44)$ & $1395 / 1319(1.06)$ & \\
\hline \multicolumn{4}{|c|}{ Dose modifications based on dose reductions and delays ( $\geq 1$ per patient) } \\
\hline Number of patient cycles & 1492 & 1319 & \\
\hline $\begin{array}{l}\text { Number of patients with dose modification(s), } \\
\mathrm{n}(\%)\end{array}$ & $115(7.7 \%)$ & $63(4.8 \%)$ & $0.016 \pi$ \\
\hline
\end{tabular}

Table 2: Relationship between response to decitabine or treatment of choice and various potential indicators of treatment efficacy and safety. ${ }^{\star}$ All patients who had both response and parameter data available. $\dagger$ Either supportive care or cytarabine. $¥ P$ values for overall survival of responders vs. non-responders. \$2 proportion Z-test to compare proportions between responders and nonresponders. $\|$ Based on zero-inflated Poisson regression model with responder (yes/no) as explanatory variable and log number of treatment cycles as offset. P1 is the P value based on the Poisson (non-"Certain Zero") component and P2 is the P value based on the binomial component. Based on logistic regression with number of treatment cycles as the number of trials and responder (yes/no) as explanatory factor. CR, complete remission; CRi, CR with incomplete blood count recovery; NS, not significant; PR, partial remission; RBC, red blood cell; and SD, standard deviation.

\section{Response and potential indicators of efficacy and safety}

This post hoc analysis of the relationship between response to treatment and various potential indicators of efficacy and safety found that significantly fewer responders than nonresponders $(\mathrm{P}=0.024)$ required IV antibiotic use (Table 2 ). Significantly more nonresponders ( $7.7 \%$ per cycle) than responders $(4.8 \%$ per cycle $)$ required dose modifications of decitabine or treatment of choice $(\mathrm{P}=0.016)$.

Using a zero-inflated Poisson model [9], the propensities of requiring platelet or red blood cell transfusions were not found to be significantly different between responders and nonresponders. However, in patients requiring transfusions, nonresponders required significantly more episodes of transfusion per treatment cycle $(\mathrm{P}<0.0001$, for both types of transfusions).

\section{Transfusion episodes and baseline white blood cell count}

Red blood cell and platelet transfusion data were further analyzed by baseline white blood cell count ( $>10 \times 10^{9} / \mathrm{L}$ vs. $\left.\leq 10 \times 10^{9} / \mathrm{L}\right)$. Consistent with the overall analysis, significant differences $(\mathrm{P}<0.0001)$ in the number of platelet or red blood cell transfusion episodes per treatment cycle were noted between responders and nonresponders for patients with baseline white blood cells $10 \times 10^{9} / \mathrm{L}$ or lower. The mean number of platelet transfusion episodes was 1.16 per treatment cycle in responders and 3.00 per cycle in nonresponders.

The mean number of red blood cell transfusion episodes was 1.44 per treatment cycle in responders and 2.98 per cycle in nonresponders. For this subpopulation, in responders and nonresponders, respectively, the total number of cycles was 1041 and 1192, the total number of platelet transfusion episodes was 728 and 2538, and the total number of red blood cell transfusion episodes was 1113 and 3025 .

For patients with baseline white blood cell counts higher than $10 \mathrm{x}$ $10^{9} / \mathrm{L}$, significant differences $(\mathrm{P}<0.0001)$ were observed between the mean number of platelet transfusion episodes (1.39 per treatment cycle for responders; 2.89 per treatment cycle for nonresponders) and the mean number of red cell transfusion episodes (1.37 per treatment cycle for responders; 2.60 per treatment cycle for nonresponders).

In responders and nonresponders, respectively, the total number of cycles was 269 and 290, the total number of platelet transfusion episodes was 297 versus 627, and the total number of red blood cell transfusion episodes was 280 and 561.

\section{Treatment response and time to first transfusion}

Little difference was seen between responders and nonresponders in the time to the first red blood cell transfusion (Figure 1A). A 
Citation: Minden MD, Arthur C, Mayer J, Jones MM, Berrak E, et al. (2015) Association between Treatment Response and Potential Indicators of Efficacy and Safety in a Phase III Trial of Decitabine in Older Patients with Acute Myeloid Leukemia. J Blood Disorders Transf 6: 251. doi:10.4172/2155-9864.1000251

Page 5 of 5

significant difference was seen between responders and nonresponders in the time to the first platelet transfusion $(\mathrm{P}=.003$; Figure $1 \mathrm{~B})$.

A

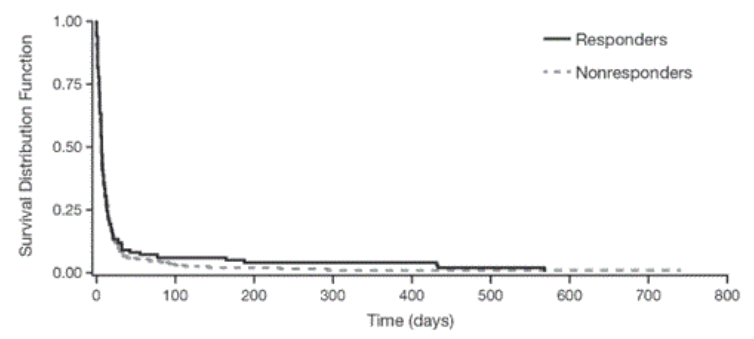

B

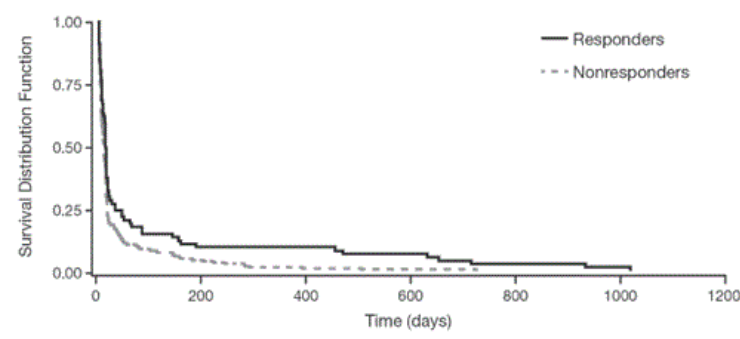

Figure 1: Time to first (A) red blood cell and (B) platelet transfusion for responders and nonresponders to decitabine or treatment of choice. A: Red blood cell transfusion,B: Platelet transfusion (log-rank $\mathrm{P}=0.003$ between responders and nonresponders).

\section{Discussion}

Results of this post hoc analysis of data from a large, international, multicenter, open-label phase III trial suggest that response to decitabine or to treatment of choice (with either supportive care or cytarabine) may be associated with a reduced requirement for dose modifications or antibiotic use and, in older patients with newly diagnosed AML, fewer transfusion episodes. The differences between responders and nonresponders in the need for antibiotic use might be confounded by the longer overall survival time of responders compared with nonresponders, which could not be addressed in this analysis due to the limited availability of data.

The time to platelet transfusion was significantly shorter in nonresponders, as might be expected. Comparison of the number of transfusion episodes per cycle by response and by baseline white blood cell count groups $\left(>10 \times 10^{9} / \mathrm{L}\right.$ or $\left.\leq 10 \times 10^{9} / \mathrm{L}\right)$ showed consistent results in that responders had a significantly lower mean number of transfusion episodes compared with that of nonresponders, when a transfusion was required.

The findings of this analysis suggest that response to decitabine or to treatment of choice may be associated with potentially clinically relevant indicators, namely, having fewer dose modifications in older patients with newly diagnosed AML.

\section{Acknowledgments}

The authors thank Yvonne E. Yarker, PhD, CMPP, of Peloton Advantage for medical writing and editorial support, and Yuhan $\mathrm{Li}$, M.S. of Eisai Inc. for statistical analysis.

\section{Author Disclosures}

M. Minden has served as a remunerated consultant for Teva. C. Arthur discloses no financial conflicts of interest. J. Mayer has served as a remunerated consultant, a member of an advisory committee or a member of the Board of Directors for Eisai Inc., and has received research grants from Eisai Inc. M. M. Jones and E. Berrak are employees of Eisai Inc. H. Kantarjian has received research grants from Eisai Inc.

\section{Clinicaltrials.gov identifier: NCT00260832}

Funding source: The original study and this analysis were funded by Eisai Inc. Assistance with medical writing, editing, and graphics was provided by Peloton Advantage and was funded by Eisai Inc.

These data were presented in part at the Annual Meeting of the American Society of Clinical Oncology, June 1-5, 2012, in Chicago, IL (abstract 6627).

\section{References}

1. www.nccn.org/professionals/physician_gls/pdf/aml.pdf

2. Fey MF, Dreyling M (2010) Acute myeloblastic leukaemias and myelodysplastic syndromes in adult patients: ESMO Clinical Practice Guidelines for diagnosis, treatment and follow-up. Ann Oncol 21: v158v161.

3. Dohner H, Estey EH, Amadori S, Appelbaum FR, Buchner T, et al. (2010) Diagnosis and management of acute myeloid leukemia in adults: recommendations from an international expert panel, on behalf of the European LeukemiaNet. Blood 115 : 453-474.

4. www.nccn.org/professionals/physician_gls/pdf/all.pdf

5. http://www.fda.gov/downloads/AdvisoryCommittees/ CommitteesMeetingMaterials/Drugs/ OncologicDrugsAdvisoryCommittee/UCM290512.pdf

6. Blum W, Garzon R, Klisovic RB, Schwind S, Walker A, et al. (2010) Clinical response and miR-29b predictive significance in older AML patients treated with a 10-day schedule of decitabine. Proc Natl Acad Sci U S A 107 : 7473-7478.

7. Cashen AF, Schiller GJ, O'Donnell MR, Dipersio JF (2010) Multicenter, phase II study of decitabine for the first-line treatment of older patients with acute myeloid leukemia. J Clin Oncol 28 : 556-561.

8. Kantarjian HM, Thomas XG, Dmoszynska A, Wierzbowska A, Mazur G, et al. (2012) Multicenter, randomized, open-label, phase III trial of decitabine versus patient choice, with physician advice, of either supportive care or low-dose cytarabine for the treatment of older patients with newly diagnosed acute myeloid leukemia. J Clin Oncol 30 : 2670-2677.

9. Lambert D (1992) Zero-inflated poisson regression, with an application to defects in manufacturing. Technometrics 34: 1-14. 